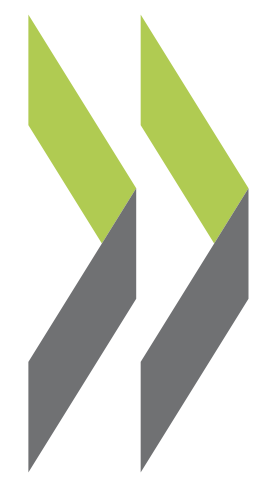

PEB Exchange, Programme on Educational Building 2003/19

\title{
An Ultra Energy-Efficient School in Quebec
}

\section{Pierre Gastaldy}




\section{AN ULTRA ENERGY- EFFICIENT SCHOOL IN QUEBEC}

For the construction of its newest school in Quebec (Canada), the Grandes-Seigneuries School Board, which has long been noted for its energy efficiency approach, wanted to set itself an especially challenging project which would reduce greenhouse gas emissions to close to zero. From an architectural standpoint, a series of simple methods, well within everyone's reach, were used in combination to reduce energy needs. This pilot project has made Le Tournant School one of the most energy efficient in Canada. The concept initiator explains.

St-Constant, a suburb of Montreal, 15 January 2003, outdoor temperature: $-16^{\circ} \mathrm{C}$ - The outside air enters Le Tournant School's ventilation system at $+5^{\circ} \mathrm{C}$, a costfree heat gain of $21^{\circ} \mathrm{C}$.

Le Tournant School, which opened in November 2002, is the most energy efficient institutional building in Quebec, the second most efficient in all of Canada. It has exceeded the minimum requirements of Canada's "Model National Energy Code for Buildings" by $60 \%$.

\section{Combining simple methods}

These results were achieved by using only simple, tried and tested methods. The school is small; with its $2682 \mathrm{~m}^{2}$, it is designed to accommodate 220 pupils. The compact

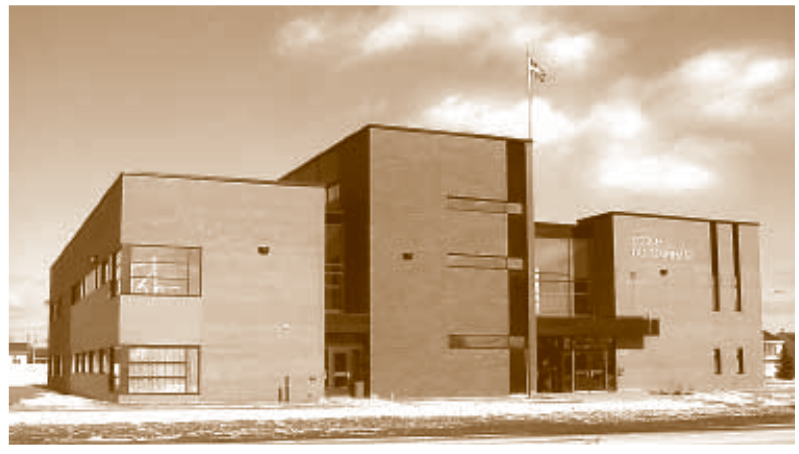

Le Tournant School, St-Constant, Quebec.

The solar walls run the full height of the building

on either side of

the central section.

architecture centres around a multi-purpose common room. The wall and roof are slightly better insulated than usual. Window orientation was optimised and lowemission glass was used in the appropriate locations. The asphalted areas are away from the building, and careful planting was used to encourage heat gain in winter and block the sun in summer. Even the colour of the bricks was selected to optimise absorption.

The mechanical engineering option selected was a closed loop geothermal system. A mix of methanol circulating through five kilometres of pipe connecting to 18 independent wells transfers heat to and from the ground. In winter, heat from the ground is transferred to the school, and in summer, heat from the school is returned to the ground. Depending on the weather conditions, the system selects one of the two air intakes which, during the heating period, pass behind one of the two solar walls (plain black perforated plate) and benefit from substantial heat gain. The fresh air intake rate is regulated by a $\mathrm{CO}_{2}$

Figure 1

Comparative performances of Le Tournant

School and other primary and secondary

schools in Quebec, particularly

those of the Grandes-Seigneuries

School Board (CSDGS)

and those with heat

pumps (HP)

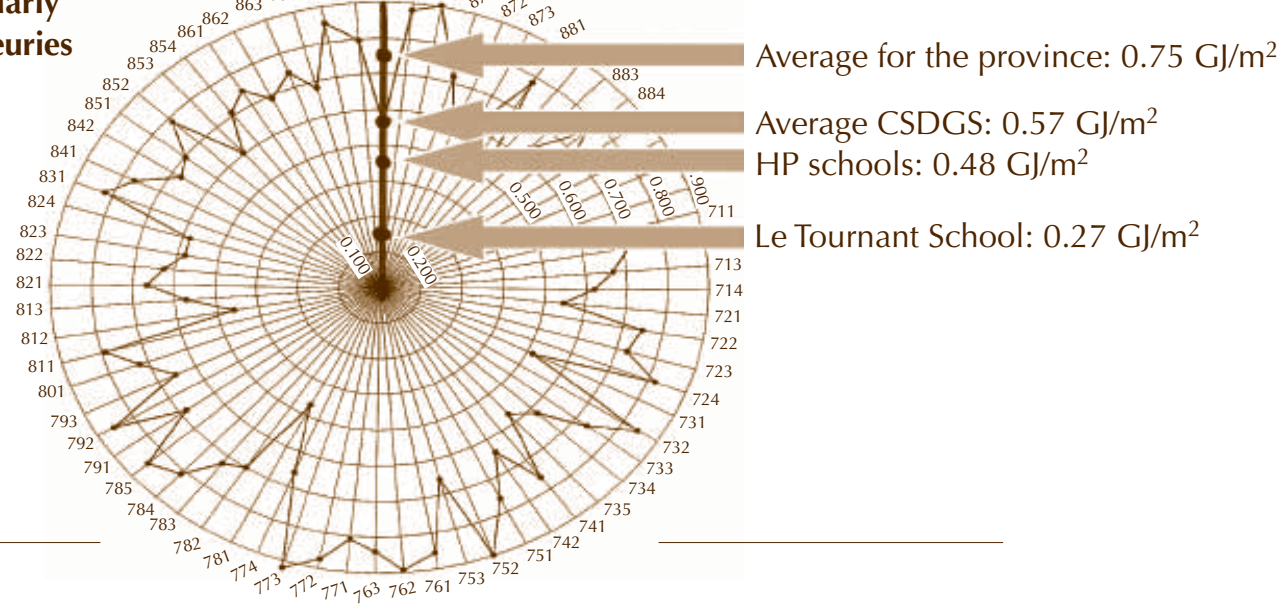


Temperatures in ${ }^{\circ} \mathrm{C}$

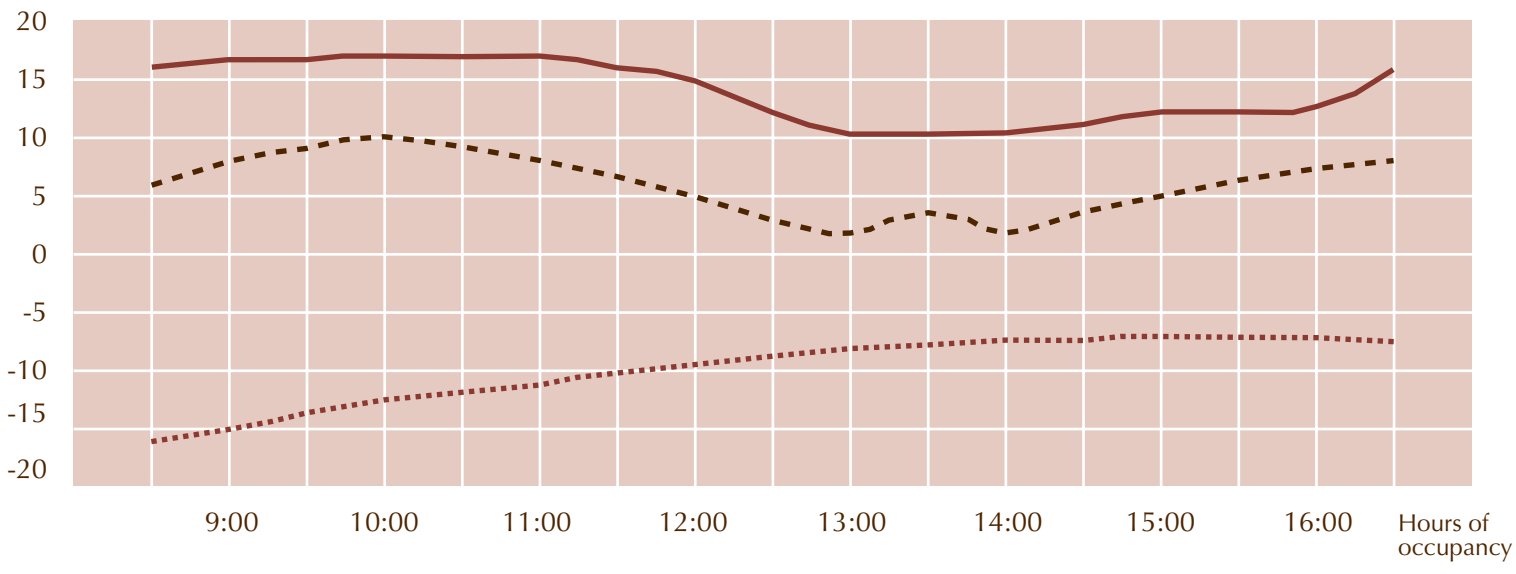

External temperature
$\ldots \ldots$............... Temperature after solar wall

The graph shows the no-cost heat gain to building intake air from the solar walls and heat recovery (on cloudy days, the gain is also remarkable and heat recovery is more efficient).

sensor. So that none of the heat is lost, a thermal tube heat exchanger is also used to heat intake air from the outside using the heat extracted from evacuated stale air. Inside the building, heating and air conditioning are ensured by 25 heat pumps. Should it be necessary, an electric coil can provide back-up. The use of electricity is reduced to the minimum so that, even though the heating coil runs on fossil fuel, the impact on $\mathrm{CO}_{2}$ emissions is negligible.

Ventilation and lighting are slaved to presence sensors, and the control of all school systems is centralised and can be remotely monitored.

\section{Daring to go over budget}

With the help of a subsidy from the Canadian Government equal to twice the expected annual savings, the budget granted by the Minister of Education was exceeded by only $10 \%$. One could speculate that on a larger scale project, the cost overrun would be even less. At current energy prices the additional cost would be recovered in ten years.

Deciding to spend more today in order to generate savings for tomorrow seems so obvious that, when I reflect on it, I deserve to be taken to task: not because of anything I did, but because I did not do it earlier. The fact is that, since the technologies used for this construction have been available - for about ten years now - I have headed the construction of six schools. While energy savings have always been a must, I never dared to "invest" budgets that I did not have in order to generate savings later.
The usual approach is to stay within the funders' budget or to ask for more, stifling any innovation by designers, who then stick to "cutting-and-pasting" standard designs. But we must remember that these facilities we are acquiring will last 40 to 60 years. So where is the risk in borrowing over ten, 15 or even 20 years? This is more apparent in the field of energy where results can be measured directly, but it is equally true for other sorts of options that reduce life cycle costs in the long term.

To conclude, I will sum up the factors that help to make a project like this possible and that are well within the reach of all. First, make a firm commitment to doing things differently, particularly as relates to the "environment". Then, force the design office to innovate, or at least to bring together as many concepts as possible that have been known for some time. Finally, dare to go over budget and put together financial packages over the lifetime of the facilities.

\section{Article by Pierre Gastaldy \\ Directeur du service des ressources matérielles Commission scolaire des Grandes-Seigneuries Quebec, Canada}

Fax: 14504444423

E-mail: gastaldy.pierre@csdgs.qc.ca 